nitric oxide was slowly weaned and the $\mathrm{FiO}_{2}$ gradually reduced to $0 \cdot 3$. The peak methaemoglobin level measured was $2 \cdot 8 \%$ on day two.

Eight days after admission to intensive care, however, he suffered a further severe pulmonary haemorrhage. Nitric oxide was again instituted at parental request, but after an initial improvement hypotension and hypoxia supervened despite the addition of intravenous adrenaline and phentolamine. He died 10 hours later.

\section{Discussion}

Idiopathic pulmonary haemosiderosis is a rare disorder of childhood characterised by recurrent episodes of bleeding into the lungs. ${ }^{1}$ This in turn causes anaemia, pulmonary fibrosis, and progressive pulmonary hypertension. It may present as either acute pulmonary bleeding or as progressive breathlessness.

Nitric oxide is a potent endogenous vasodilator produced by vascular endothelium. ${ }^{2}$ It is rapidly bound and inactivated by haemoglobin (producing methaemoglobin) and when added to inspired gases causes localised pulmonary vasodilatation without systemic effects. It has recently been shown to be effective in treating persistent pulmonary hypertension of the newborn, ${ }^{3}$ as well as pulmonary hypertension associated with congenital heart defects ${ }^{4}$ and adult respiratory distress syndrome. ${ }^{5}$

This child was known to have a degree of raised pulmonary vascular resistance. It is likely that this was compounded by hypoxia and acidosis to produce profound vasoconstriction of the pulmonary vascular tree. The ensuing right ventricular dilatation and failure would cause severe systemic circulatory embarrassment.

Conventional vasodilators have been used in this situation but are limited by their systemic effects. Inhaled nitric oxide is rapidly bound to haemoglobin and appears to be devoid of systemic vasodilator action. Furthermore, nitric oxide will have an effect only on ventilated areas of lung and thereby should improve rather than disrupt ventilation-perfusion matching. It is interesting to note that after starting nitric oxide not only did oxygenation improve, but carbon dioxide levels decreased, despite an unchanged minute ventilation. This would suggest a reduction in physiological deadspace.

Nitric oxide can only be a short term adjuvant treatment, but may find a role in reversing critical hypoxic pulmonary vasoconstriction. In low doses (up to $20 \mathrm{ppm}$ ) it appears to be safe for up to several weeks, ${ }^{4}$ but methaemoglobin levels should be monitored closely. Ideally the inspired nitric oxide and nitrogen dioxide concentrations should be monitored. 1 Soergel KH, Sommers SC. Idiopathic pulmonary 32: 499-511.

2 Moncada S, Palmer RMJ, Higgs EA. Nitric oxide: physiology, pathophysiology, and pharmacology. Pharmacol Rev 1991; 43: 109-42.

3 Roberts JD, Polaner DM, Lang P, Zapol WM. Inhaled nitric oxide in persistent pulmonary hypertension of the newoxide in persistent pulmonary
born. Lancet 1992; 340: 818-9.

4 Haydar A, Mauriat P, Pouard P. Inhaled nitric oxide for postoperative pulmonary hypertension in patients with congenital heart defects. Lancet 1992; 340: 1545

5 Rossaint R, Falke KJ, Lopez F, Slama K, Pison U, Zapol WM. Inhaled nitric oxide for the adult respiratory distress syndrome. $N$ Engl $f$ Med 1993; 328: 399405.

\title{
Can we improve diabetes care in schools?
}

\author{
M A Tatman, D N Lessing
}

\begin{abstract}
Results of a questionnaire study showed that parents were dissatisfied with school care of their children's diabetes and with teachers' knowledge of diabetes. Parents were more satisfied with support in school if a paediatric diabetes liaison service was provided rather than an adult one.

(Arch Dis Child 1993; 69: 450-451)
\end{abstract}

Epidemiology and Biostatistics Unit, Institute of Child Health, London

M A Tatman

Community Health Unit, Upton Hospital, Albert Street, Slough SL1 2BJ

D N Lessing

Correspondence to: Dr Lessing.

Accepted 25 June 1993
Surveys of teachers ${ }^{12}$ and parents $^{34}$ have revealed problems with teachers' knowledge of diabetes. A national study of parents' satisfaction with diabetes care in the first year after their child's diagnosis found $37 \%$ were dissatisfied with school care and $50 \%$ were concerned about teachers' knowledge. ${ }^{5}$ We used information from that study to examine services available to schoolchildren, comparing paediatric and adult diabetes liaison services with respect to parental satisfaction with school care.

\section{Method}

Of the 469 (92\%) parents returning questionnaires, 351 answered the questions on school. Information on each child's place of residence hospital, and paediatrician ${ }^{5}$ was used to identify the service available to the child in the year after diagnosis (1988-9). The liaison service then covering each health district was identified in the British Diabetic Association (BDA)/Royal College of Nursing Directory of nurses with a special interest in diabetes (January 1989). If necessary the type or catchment area of the liaison service then provided was identified by the current liaison nurse.

Classifying children into those covered by adult and those covered by paediatric services (paediatric home care teams covering diabetes, paediatric diabetes nurse specialists, and paediatric diabetes health visitors) was straightforward for the $87 \%$ who were treated in their home district. Children treated outside their home district were classified according to 
the type of service covering their home district unless their paediatrician had a diabetes liaison service which covered them.

Time off school, diabetes related problems in school, school visits by the liaison service, teachers' knowledge of diabetes, and parental satisfaction with support and information in school were compared between children covered by paediatric and by adult services.

\section{Results}

Adult services covered $226(65 \%)$ children, paediatric services $103(29 \%)$, and no service was identified for $22(6 \%)$. There was no difference in mean age of children covered by adult and by paediatric services.

No significant differences were found between children with adult and paediatric services in the time lost from school, or in the proportions with diabetes related problems in school.

For only 171 (49\%) children had there been a school visit by the liaison service. Children covered by paediatric services were 1.5 times ( $95 \%$ confidence interval $1 \cdot 2$ to $1 \cdot 7, p=0.001$ ) more likely to get a school visit with $67(65 \%)$ doing so compared with $104(46 \%)$ of those covered by adult services. Parents whose children received a paediatric service were also more satisfied with information and support in school (table). Overall, 200 (57\%) parents said teachers lacked know-ledge of diabetes, but this proportion did not differ between adult and paediatric services.

When parents were asked to comment about diabetes services, 292 (55\%) of 531 comments concerned school. Of these, $198(67 \%)$ related to teachers' lack of knowledge, 103 of which mentioned management of diet and of hypoglycaemia. Thirty comments concerned poor communication between teachers or uncaring attitudes, although 14 said the school was caring and understanding. Other comments concerned difficulties with school trips, mood changes, and deterioration in school work. Parents made 37 comments on improving school care, 31 suggesting school visits by professionals, and six suggesting an educational video for teachers.
Parental satisfaction with school support provided by adult and paediatric diabetes liaison services; number (\%)

\begin{tabular}{lcc}
\hline Satisfaction & Adult & Paediatric \\
\hline Very satisfied & $24(13)$ & $26(29)$ \\
Satisfied on the whole & $88(46)$ & $43(47)$ \\
Somewhat dissatisfied & $42(22)$ & $15(17)$ \\
Very dissatisfied & $36(19)$ & $7(7)$ \\
Total $^{\star}$ & $190(100)$ & $91(100)$
\end{tabular}

«48 'don't know'.

$\chi^{2}$ for trend $=13 \cdot 5, \mathrm{df}=1, \mathrm{p}=0.0002$.

\section{Discussion}

Children with diabetes spend considerable time at school; this time should be both tolerable and safe. The BDA recommends a school visit for every child, followed up at least yearly. ${ }^{6}$ Disappointingly it appears that many paediatric nurses did not visit schools, although they were more likely to than adult nurses. Parents were more satisfied with paediatric nurses, but this did not improve their opinions of teachers' knowledge.

We therefore recommend that a trained paediatric diabetes nurse should talk to the class teacher, games teacher, dinner lady, playground supervisors, school doctor and nurse, before the child returns to school. Information must cover the main areas of concern, hypoglycaemia and diet. Information packs and telephone numbers should be supplied. The paediatric diabetes nurse should revisit the school at least yearly and liaise with the school health service.

MAT holds an MRC Health Services Research Training Fellowship. We thank Adele McEvilly for her help.

1 Bradbury AJ, Smith CS. An assessment of the diabetic knowledge of school teachers. Arch Dis Child 1983; 58: 692-6.

2 Warne J. Diabetes in school: a study of teachers' knowledge and information sources. Practical Diabetes 1988; 5: $210-5$.

3 Challen AH, Davies AG, Williams RJW, Baum JD. Support for families with diabetic children: parents' views. Practical Diabetes 1990; 7: 26-31.

4 Kauffman L, Bradbury AJ, Comer L. Experience of diabetic children and their families in relation to diet at school.
chen $\mathrm{L}$, Bradbury AJ, Comer L. Experience of diabetic Practical Diabetes 1990; 4: 166-70.

5 Lessing DN, Swift PGF, Baum JD, Metcalfe MA. Newly diagnosed diabetes: a study of parental satisfaction. Arch Dis Child 1992; 67: 1011-3.

6 British Diabetic Association Committee. What professional supervision should children with diabetes and their families expect? London: British Diabetic Association, 1989.
Hospital for Sick

Children, London, Department of Infectious Diseases

Julian Shield

Vas Novelli

Diana Gibb

Department of

Gastroenterology

Colin Melville

Peter Milla

Department of

Histopathology

Glenn Anderson

Irene Scheimberg

Correspondence and reprint requests to: Dr Vas Novelli, requests to: Dr Vas Novious Diseases Unit,

Hospital for Sick Children,

Great Ormond Street,

Great Ormond Street,
London WC1N 3JH.

Accepted 6 June 1993

\section{Bovine colostrum immunoglobulin concentrate for cryptosporidiosis in AIDS}

\author{
Julian Shield, Colin Melville, Vas Novelli, Glenn Anderson, Irene Scheimberg, Diana \\ Gibb, Peter Milla
}

\author{
Abstract \\ Lactobin- $R$ is a commercial hyperimmune \\ bovine colostrum with potent anticrypto- \\ sporidial activity. It was administered to a \\ 4 year old child with AIDS and severe diar- \\ rhoea associated with cryptosporidiosis.
}

There was significant clinical improvement in the diarrhoea and permanent elimination of the parasite from the gut as assessed through serial jejunal biopsy and stool specimens.

(Arch Dis Child 1993; 69: 451-453) 